\title{
MERCADO DE TRABALHO FORMAL E RENDIMENTOS DA AGROINDÚSTRIA SUCROENERGÉTICA DE 2000 A 2016
}

\author{
LeANDro Gilio * \\ Nicole Rennó Castro ${ }^{\dagger}$ \\ LUCIANO RODRIGUES $\ddagger$ \\ Mirian Rumenos Piedade Bacchi $\S$
}

\begin{abstract}
Resumo
Analisa-se a evolução do mercado de trabalho da agroindústria sucroenergética de 2000 a 2016 por meio de uma base atualizada de dados e uma nova reflexão sobre o impacto de aspectos institucionais e conjunturais relacionados ao setor. A avaliação foi conduzida a partir de análises descritivas e equações de rendimento. Também se propôs uma nova classificação de trabalhadores entre atividades intrassetoriais. Como resultados, verifica-se que a nova abordagem revelou maior concentração de trabalhadores no segmento agrícola comparativamente a estudos anteriores. Destaca-se também o declínio de postos a partir de 2008 como efeito da mecanização e da crise no setor, mas com evolução na qualidade.
\end{abstract}

Palavras-chave: mercado de trabalho, indicadores sociais, setor sucroenergético, equação de rendimentos.

\begin{abstract}
We evaluated the evolution of the sugarcane industry labor market from 2000 to 2016 through an updated database and a new reflection on the impact of institutional and conjunctural aspects related to the sector. Our evaluation was conducted based on descriptive analyses and earnings equations. Our study also proposed a new classification of workers between intrasectoral activities. The results ensure that the new approach revealed a higher concentration of workers in the agricultural segment, compared to previous studies. Also noteworthy is the decline in posts from 2008 on, the effect of mechanization, and the crisis in the sector, but with job quality evolution.
\end{abstract}

Keywords: labor market, social indicators, sugarcane industry, earnings equation.

JEL classification: J43, Q26, O15.

DOI: http / / dx.doi .org/10.11606/1980-5330/ea151478

\footnotetext{
* Insper, Centro de Agronegócio Global, Brasil. E-mail: leandrog3@insper.edu.br

† Universidade Federal de São João del-Rei (UFSJ) e Centro de Estudos Avançados em Economia Aplicada (Cepea), Brasil. E-mail: renno.nicole@gmail.com

‡ Escola Superior de Agricultura Luiz de Queiroz da Universidade de São Paulo (ESALQ-USP), Brasil. E-mail: lurodrig@usp.br

$\S$ Escola Superior de Agricultura Luiz de Queiroz da Universidade de São Paulo (ESALQ-USP), Brasil. E-mail: mrpbacch@usp.br
} 


\section{Introdução}

A emergência da economia de baixo carbono e a busca mundial por fontes alternativas e renováveis de energia geraram uma expansão significativa da produção e do consumo de biocombustíveis de base agrícola nas últimas décadas. Atualmente, mais de 64 países possuem programas nacionais para o uso de biocombustíveis e, com os compromissos assumidos por mais de 190 nações na Conferência do Clima de 2015 em Paris (COP-21), houve um importante reforço no papel da referida fonte na matriz energética mundial futura (Kutas et al. 2016). Como efeito, foram criadas possibilidades de desenvolvimento econômico, emprego e renda, notadamente em países em desenvolvimento na América Latina, África e Ásia, e em áreas rurais, que em geral são bastante defasadas em relação a seus indicadores socioeconômicos quando comparados às áreas urbanas ou industriais.

O caso brasileiro, neste contexto, desponta-se como relevante objeto de análise, principalmente pela experiência histórica e singular ao país na produção e no uso de etanol combustível em larga escala, iniciada com o programa governamental Proálcool (Programa Nacional do Álcool) e a introdução dos veículos dedicados a etanol (E100) ao final da década de 1970. Desde então, houve grande expansão das regiões produtoras de cana-de-açúcar e, com isso, diferentes impactos e oportunidades de desenvolvimento socioeconômicos relacionados à atividade, principalmente no que se refere à criação de postos de trabalho, de maneira direta e indireta (Moraes \& Zilberman 2014, Gilio 2015).

A agroindústria sucroenergética brasileira em sua história recente passou por importantes transformações e mudanças institucionais que impactaram diretamente o seu desenvolvimento, tanto no mercado de etanol quanto no de açúcar, com destaque ao início da desregulamentação do setor, na década de 1990, e o surgimento dos veículos bicombustíveis em 2003.

Esses dois fatos permitiram um intenso crescimento de oferta e da demanda por açúcar brasileiro e etanol combustível, que seguiu aquecida até 2008, gerando investimentos e elevação da competitividade na atividade (Moraes \& Zilberman 2014). Houve, no período, um processo de redefinição da estrutura de mercado e de produção por meio de um movimento de fusões e aquisições de empresas e da entrada de capital estrangeiro (Moraes 2007, Beiral 2011, Gilio 2015). Segundo Moraes (2007), tais transformações geraram impactos importantes sobre o mercado de trabalho relacionado ao setor, com destaque à terceirização de serviços agrícolas e industriais e, especialmente, ao processo de mecanização do corte e plantio da cana-de-açúcar. Este último aspecto também se relaciona à proibição da queima da cana-de-açúcar como método de despalha, que incentivou a adoção da mecanização da colheita, reduzindo a demanda por mão-de-obra no campo, mas com ganhos ambientais e de qualidade dos empregos gerados (Moraes 2007, Gilio 2015).

A partir de 2009, iniciou-se um período de crise e maior cautela de investimentos na atividade sucroenergética. Vários fatores são apontados na literatura na configuração deste cenário: a política de controle de preços da gasolina executada pela ação governamental desde 2006; a baixa previsibilidade de políticas energéticas, as desonerações promovidas sobre os combustíveis fósseis como medida de controle inflacionário, os incentivos preferenciais governamentais a outras fontes energéticas; o incremento crescente dos custos trabalhistas; os efeitos da mecanização e, ainda, as restrições à aquisição de terras por estrangeiros, que limitaram investimentos, entre outros (Solowiejczyk 
\& Costa 2013, Moraes et al. 2014, Gilio et al. 2015, Gilio \& Castro 2016). Entre 2008 e 2014, 83 usinas foram fechadas devido a dificuldades financeiras, sendo 64 destas localizadas no Centro-Sul do país, principal região produtora (Santos et al. 2015). Esse processo de fechamento de usinas e a mecanização da colheita, induzida pelas pressões ambientais e pelos custos trabalhistas, impactaram diretamente o mercado de trabalho da atividade.

Nesse contexto de mudanças institucionais, mercadológicas e tecnológicas do setor, diversos estudos buscaram avaliar a evolução de indicadores do mercado de trabalho da agroindústria sucroenergética, destacando sua dimensão e relevância.

Moraes (2007) realizou uma análise destacando a dimensão de crescimento do número de trabalhadores e formalização no setor de 2000 a 2005. Avaliando o Brasil como um todo, tal estudo considera que, no período, houve aumento expressivo de 52,9\% no número de empregados na atividade, com o contingente passando de 642.848 em 2000 para 982.604 em 2005, com destaque ao aumento na formalização e qualidade dos empregos gerados ao longo do tempo. Hoffmann \& Oliveira (2008), por sua vez, também destacaram a grande importância do setor no segmento agrícola, dimensionando-o em 608,3 mil trabalhadores na produção de cana em 2006. Oliveira (2009) apontou que, em 2007, havia 527.401 pessoas ocupadas na cultura de cana, que corresponderam a $19,9 \%$ do total de empregos gerados na agricultura brasileira daquele ano. Já Toneto Junior \& Liboni (2008), avaliando o período de 1994 a 2006, identificaram que a remuneração do setor não se distingue daquela de outros setores industriais brasileiros e tende a ser maior com relação a outras culturas quando no segmento agrícola.

Tais estudos lançaram foco sobre a avaliação da importância do mercado de trabalho do setor, em termos de dimensão, e qualidade dos empregos gerados, em período de grande crescimento da atividade sucroenergética no Brasil (entre 2000 e 2007), tanto na área agrícola como industrial. Em período posterior, Baccarin et al. (2011) e Baccarin (2015) avaliaram as ocupações na indústria canavieira, com destaque para a análise do efeito da mecanização sobre o número de pessoas ocupadas no setor no período de 2007 a 2012. Entre outros resultados, os autores evidenciaram que houve redução no número de trabalhadores canavieiros no período de mecanização, em contraste com o movimento observado em outras atividades econômicas no país de modo geral. Silva et al. (2019), em uma abordagem de Modelos Aplicados de Equilíbrio Geral, simularam impactos da mecanização e também avaliaram redução expressiva do contingente de mão de obra empregado na produção de canade-açúcar até 2031.

Mesmo com diversos estudos já publicados na área, identifica-se que existem lacunas ainda não exploradas na literatura disponível. Mais particularmente, dois aspectos relevantes e que certamente impactaram este mercado no período recente merecem maior atenção: (i) os efeitos diretos da eliminação gradual do processo de queima da cana-de-açúcar e a consequente mecanização da colheita e, posteriormente, do plantio; (ii) e os efeitos do ciclo de crise do setor, verificado a partir de 2008.

$\mathrm{O}$ primeiro aspecto (i) remete à mudança institucional que exigiu uma transformação significativa no sistema de produção da cultura canavieira. Já o segundo (ii), tem origem em fatores de ordem financeira, agronômica e mercadológica, mas também são fortemente associados a políticas governamentais e questões institucionais relevantes (Moraes \& Zilberman 2014, Moraes \& Bac- 
chi 2014, Gilio \& Castro 2016, Rodrigues \& Bacchi 2016). Ambos os processos certamente exerceram efeitos relevantes sobre o mercado de trabalho do setor sucroenergético, mas que ainda não foram dimensionados e avaliados com as informações mais recentes. Isso posto, no presente estudo se busca avaliar a evolução dos indicadores do mercado de trabalho formal dos setores de canade-açúcar, açúcar e etanol para o período de 2000, início do livre mercado, até 2016.

Neste estudo, busca-se atualizar os dados publicados sobre o tema, mas também oferecer uma reflexão analítica mais detalhada sobre o impacto de aspectos institucionais e conjunturais ao longo do período mencionado. Também são calculadas equações de rendimento, de modo a se obter informações sobre os determinantes do nível de salário dos trabalhadores do setor sucroenergético. Nesta análise, diferente de trabalhos anteriores disponíveis na literatura que se concentram na avaliação de dados de corte transversal, utiliza-se a metodologia de dados em painel, que apresenta vantagens ao se incorporar a dimensão temporal, além de se controlar características não observáveis dos trabalhadores do setor.

Por fim, no trabalho adota-se uma proposta metodológica de classificação intrassetorial das atividades dos trabalhadores da agroindústria sucroenergética, com aprimoramento fundamental em relação a outros estudos disponíveis. Diferentemente dos métodos de classificação geralmente utilizados em estudos anteriores, que lançam foco apenas à atividade fim da empresa contratante por meio da Classificação Nacional de Atividades Econômicas (CNAE) (ver Moraes (2007); Toneto Junior \& Liboni (2008), entre outros), apresenta-se neste estudo a segmentação por meio da atividade fim do trabalhador, baseada nos registros na Classificação Brasileira de Ocupações (CBO). Tal modificação, que será melhor detalhada na seção seguinte, visa oferecer resultados mais robustos e maior aderência da análise à realidade desta indústria.

Em síntese, ao promover uma atualização das informações sobre o setor, identificar e quantificar os determinantes do rendimento dos trabalhadores nessa indústria, propor uma abordagem metodológica diferenciada e promover uma avaliação para um horizonte temporal mais longo, este presente estudo amplia o entendimento sobre o assunto, oferecendo informações importantes para ações no âmbito dos agentes públicos e privados. Particularmente, os resultados gerados devem permitir reflexões importantes sobre o impacto das políticas públicas sobre a estrutura de emprego em um dos setores mais dinâmicos do agronegócio brasileiro.

\section{Metodologia e fonte de dados}

Este estudo utiliza como base de dados principal os registros da RAIS, do Ministério do Trabalho e Emprego, que se constitui em um censo do mercado de trabalho formal brasileiro, em que a unidade de análise é o estabelecimento e seus vínculos empregatícios. O período de análise compreende os anos de 2000 a 2016.

Em uma primeira etapa de apresentação dos resultados, é feita uma análise exploratória e descritiva de caráter agregado de dados do setor sucroenergético (que considera a produção de cana-de-açúcar, açúcar e etanol), organizados em tabelas e gráficos, considerando os critérios de subdivisão que são apresentados na subseção 2.1. Na segunda etapa, foi realizada a estimação 
de equações de rendimentos, buscando-se explorar como evoluíram os diferenciais de salário no setor, tanto no período de expansão quanto no período de declínio da atividade, passando pelo processo de mecanização, conforme estratégia empírica apresentada na subseção 2.2.

Importante destacar que os dados de emprego presentes na RAIS têm como limitação a abordagem restrita ao mercado formal, não havendo qualquer mensuração ou informação relativa a ocupações sem registro. Para se avaliar o mercado informal, existe a possibilidade do uso de dados da Pesquisa Nacional por Amostra de Domicílios (PNAD), do Instituto Brasileiro de Geografia e Estatística (IBGE), que apresenta amostras relativas tanto ao mercado formal quanto informal de trabalho brasileiro. Porém, pelo caráter amostral, análises baseadas na PNAD tornam-se limitadas no que tange a níveis mais altos de desagregação (seja setorial ou regional), podendo implicar em baixa precisão das informações. Como nessa pesquisa o foco de análise é um setor específico, com desagregação regional e por atividade do trabalhador, o uso dos microdados da PNAD não seria adequado.

Além disso, o setor sucroenergético, como característica, apresenta nível de formalidade elevado comparativamente à média brasileira de modo geral ou a outras atividades de base agropecuária. Para fins de comparação, na Tabela 1, apresentam-se informações provenientes da PNAD sobre o nível de formalização do setor sucroenergético de modo agregado, para o Brasil como um todo e para as principais macrorregiões produtoras (Centro-Sul e Nordeste).

Como comparação, de acordo com Castro et al. (2016), no agronegócio como um todo a informalidade representou cerca de $67 \%$ dos postos de trabalho, contra 33\% da média dos demais setores da economia (com base nos dados de 2014 PNAD Contínua). Tal fato indica que, no caso do setor sucroenergético, a análise limitada ao mercado formal não apresenta distorção significativa da realidade observada no período em análise. Deste modo, neste estudo optou-se por limitar a análise ao mercado formal do trabalho no setor sucroenergético, utilizando-se apenas dados provenientes da RAIS, que permitem também, como já mencionado, uma maior desagregação regional e por atividade do trabalhador.

Tabela 1: Percentual de trabalhadores informais ${ }^{a}$ no setor sucroenergético

\begin{tabular}{c|r|r|r|r|r|r|r|r|r|r|r|r|r|r}
\hline & $\mathbf{2 0 0 3}$ & $\mathbf{2 0 0 4}$ & $\mathbf{2 0 0 5}$ & $\mathbf{2 0 0 6}$ & $\mathbf{2 0 0 7}$ & $\mathbf{2 0 0 8}$ & $\mathbf{2 0 0 9}$ & $\mathbf{2 0 1 1}$ & $\mathbf{2 0 1 2}$ & $\mathbf{2 0 1 3}$ & $\mathbf{2 0 1 4}$ & $\mathbf{2 0 1 5}$ \\
\hline Brasil & $\mathbf{3 0 , 5}$ & $\mathbf{2 8 , 6}$ & $\mathbf{3 0 , 1}$ & $\mathbf{2 8 , 6}$ & $\mathbf{2 5 , 3}$ & $\mathbf{1 9 , 3}$ & $\mathbf{2 0 , 2}$ & $\mathbf{2 0 , 5}$ & $\mathbf{1 6 , 7}$ & $\mathbf{1 5 , 9}$ & $\mathbf{1 3 , 2}$ & $\mathbf{1 2 , 7}$ \\
Nordeste & 45,8 & 43,9 & 45,6 & 41,9 & 36,6 & 33,7 & 33,5 & 33,9 & 30,9 & 22,5 & 23,3 & 19,3 \\
Centro-Sul & 16,3 & 14,2 & 16,1 & 15,0 & 13,4 & 9,6 & 10,6 & 10,1 & 10,2 & 12,7 & 9,0 & 9,9 \\
\hline
\end{tabular}

Fonte: elaboração própria com base na PNAD (IBGE, 2003 a 2017).

\footnotetext{
${ }^{a}$ São considerados informais trabalhadores das categorias sem carteira assinada; conta própria e não remunerado, classificação também utilizada em Castro et al. (2016)
}

\subsection{Método de classificação de atividades}

Os estudos relacionados a análises setoriais do mercado de trabalho que fazem uso dos dados da RAIS, de modo geral, utilizam como critério de classificação dos trabalhadores a Classificação Nacional de Atividades Econômicas (CNAE), que estabelece códigos de atividades econômicas aplicados aos agentes que 
se engajam na produção de bens e serviços (Moraes 2007, Toneto Junior \& Liboni 2008, Castro et al. 2016). Como já destacado, os dados da RAIS, do Ministério do Trabalho e Emprego, são fornecidos pelos empregadores e as CNAEs avaliadas classificam a atividade econômica principal dos mesmos.

Classifica-se no setor sucroenergético as atividades agrícolas, de cultivo de cana de açúcar e as atividades industriais, que são presentes nas usinas de produção de açúcar e etanol. As usinas produtoras de açúcar e etanol utilizam três principais arranjos organizacionais para garantir o suprimento de cana-de-açúcar: i) a produção da cana-de-açúcar gerenciada pela própria empresa industrial (agroindústrias); ii) a produção da cana-de-açúcar gerenciada a partir de companhia agrícola vinculada à indústria; iii) a compra de canade-açúcar de fornecedores especializados. A maior parte das empresas do setor produz uma proporção elevada da cana-de-açúcar que processa, na qual apenas aproximadamente $40 \%$ da matéria-prima é adquirida de terceiros. A Figura 1 apresenta dados sobre a proporção de cana-própria e proveniente de fornecedores moída em usinas da região Centro-Sul, principal região produtora.

Figura 1: Proporção de cana-de-açúcar por origem utilizada em moagem nas usinas da região Centro-Sul

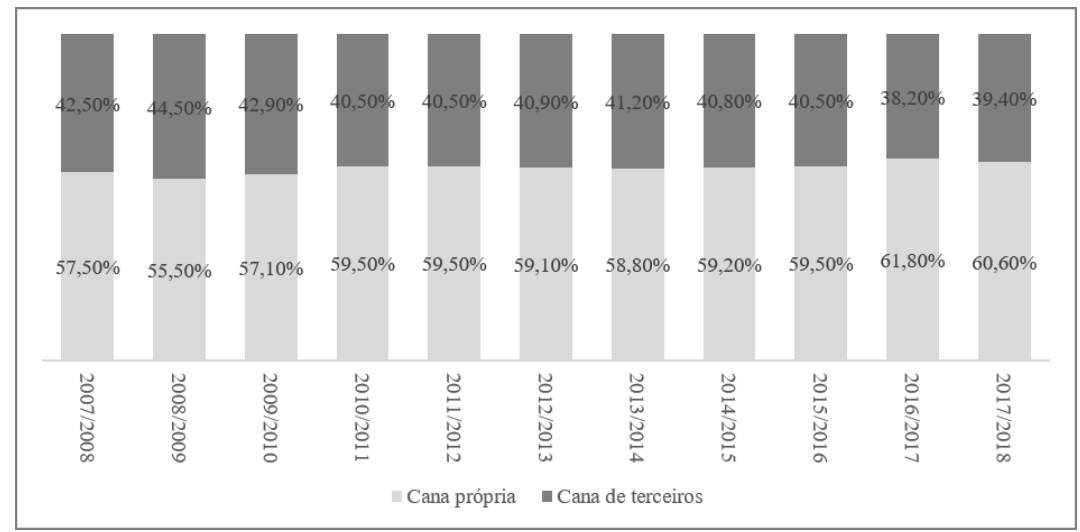

Fonte: UNICADATA (2018)

Tendo em vista a elevada verticalização do setor sucroenergético, seja por meio das agroindústrias ou de companhia agrícola vinculada à unidade industrial, a classificação de trabalhadores apenas por meio do critério de CNAEs da atividade principal da empresa contratante pode levar a erros de interpretação na avaliação intrassetorial. Especificamente, trabalhadores da produção primária da cana-de-açúcar em empresas verticalizadas são classificados como pertencentes à CNAE que se refere ao elo industrial do setor (atividade fim principal), resultando em superestimação dos empregos nesses elos e, analogamente, em subestimação dos empregos no campo. Percebe-se, deste modo, que análises intrassetoriais sobre evolução de indicadores de dimensão, características médias ou salários, baseadas na classificação por atividade econômica, podem levar a resultados enviesados.

Isso posto, neste presente estudo, como já destacado, propõe-se uma classificação dos trabalhadores em duas etapas. Primeiramente, os trabalhadores foram agregados tendo como origem as CNAEs relativas ao setor sucroener- 
gético $^{1}$. Em uma segunda etapa, estes trabalhadores foram reclassificados intrassetorialmente entre as atividades agrícolas e industriais por meio de suas ocupações dentro do setor, avaliadas a partir dos do Código Brasileiro de Ocupações - CBO. O uso da CBO para a classificação dos trabalhadores do setor sucroenergético também foi adotado por Baccarin et al. (2011) especificamente para a segregação das pessoas ocupadas na área agrícola e não agrícola, porém com critérios e lógica de análise distintas das adotadas neste presente estudo.

Com a avaliação dos CBOs, os trabalhadores foram classificados dentro do setor em 3 atividades: (i) agrícola, que corresponde as atividades relativas ao plantio, cultivo e colheita de cana-de-açúcar; (ii) industrial, que corresponde às atividades de produção de açúcar e etanol nas usinas; e (iii) administrativo/outros, que correspondem às atividades de administração, serviços ou de apoio no setor.

Neste estudo também se optou pela não separação entre trabalhadores industriais na produção de etanol e açúcar, tendo em vista que quase $80 \%$ da produção brasileira é realizada por usinas do tipo mistas, que produzem ambos os produtos, sendo, portanto, difícil separar os trabalhadores das áreas comuns de moagem, tratamento de caldo, etc. entre aqueles vinculados à produção de etanol e aqueles relativos à fabricação de açúcar (CONAB 2017).

\subsection{Equações de rendimentos}

A análise de dados médios sobre salários e quantidades de empregos entre atividades dentro do setor sucroenergético, embora forneça elementos importantes sobre a dinâmica deste mercado, não permite uma avaliação detalhada acerca dos salários dos indivíduos e de seus determinantes. Dessa forma, estimaram-se, neste estudo, equações de rendimentos, tomando por base os microdados identificados da RAIS, que permitem o acesso às informações de cada trabalhador ${ }^{2}$. Com isso, buscou-se explorar como evoluíram os diferenciais de salários dentro do setor diante de diferentes características socioeconômicas, do trabalho e locacionais dos indivíduos, tanto no período de expansão, quanto no período de declínio da produção e aumento da mecanização. Nessa etapa do trabalho, são comparados três biênios: 2003 e 2004, 2007 e 2008, e 2015 e 2016, sendo estimada uma equação de rendimentos para cada um.

A opção pela organização em biênios foi realizada de tal modo a se obter um painel de dados individuais, o que possibilitou o uso de uma abordagem de efeitos aleatórios ${ }^{3}$ para controlar as heterogeneidades não observadas entre os indivíduos que impactam os rendimentos e que são correlacionadas com as variáveis explicativas incluídas no modelo.

\footnotetext{
${ }^{1}$ CNAEs relativas ao setor sucroenergético utilizadas, com código de Classe (CNAE 2.0): 01.13-0 (cultivo de cana-de-açúcar); 10.71-6 (Fabricação de açúcar em bruto); 10.72-4 (Fabricação de açúcar refinado); 19.31-4 (Fabricação de álcool).

${ }^{2}$ A utilização destes dados foi autorizada em acordo de cooperação técnica com o Ministério do Trabalho, vinculada ao compromisso de sigilo dos pesquisadores em relação aos dados individuais de pessoas físicas (Extrato de Acordo de Cooperação Técnica 21/11/2017, publicado no Diário Oficial da União de 06/12/2017, seção 3, página 136).

${ }^{3} \mathrm{O}$ uso de dados em painel, de modo geral, pode ser estimado por um modelo de efeitos fixos ou aleatórios. A diferenciação entre estes se dá pelos efeitos não correlacionados com os regressores no modelo, e não se esses efeitos são estocásticos ou não (Greene 2008). No caso, com o grande número de variáveis explicativas do tipo categórica, recomenda-se na literatura o uso de modelos de efeitos aleatórios.
} 
A especificação do modelo econométrico seguiu a estrutura já consagrada na literatura sobre o tema, tendo como variável dependente o logaritmo neperiano do salário real médio recebido por hora trabalhada (lnsalhora). Segundo Hoffmann \& Ney (2004), o uso do modelo log-linear é adequado diante da elevada assimetria de distribuição dos rendimentos e efeitos aproximadamente multiplicativos das variáveis explicativas. Portanto, foram estimadas equação anuais descritas conforme a equação (1):

$$
\text { lnsalhor } a_{i}=\alpha+\delta_{j} H_{i}+\beta_{s} X_{i}+\varepsilon_{i}
$$

Em (1), $i$ representa os trabalhadores do setor sucroenergético; $\alpha$, o termo constante e $\varepsilon_{i}$, os erros aleatórios; $H_{i}$ é o vetor de variáveis explicativas baseadas na Teoria do Capital Humano, representadas nesse estudo por variáveis categóricas para nível de instrução e idade; $\delta_{j}$ o vetor de coeficientes relacionado; $X_{i}$ é o vetor com variáveis de controles adicionais com respectivos coeficientes $\beta_{s}$. Em resumo, considerou-se, na especificação, as seguintes variáveis:

- Binárias para diferenciar o tipo de ocupação, entre agrícola (agr), industrial (ind) e administrativa (adm), sendo a última a categoria-base.

- Binária para os níveis de instrução, tendo as seguintes categorias: indivíduos analfabetos (descol1), com de 1 a 5 anos de estudo (descol2), de 6 a 9 anos de estudo (descol3), de 10 a 12 anos de estudo (descol4) e com mais de 13 anos de estudo (descol5), sendo descol1, ou os indivíduos sem instrução, a categoria-base.

- Idade e idade ao quadrado, utilizadas na literatura como proxy para experiência no trabalho, sendo que o termo quadrático visa captar a não linearidade dessa relação.

- Sexo (sex), por meio de uma binária que assume 1 para masculino e 0 para feminino;

- Tamanho do estabelecimento, por meio de três binárias para estabelecimentos: pequenos, com até 9 empregados; médios, com 10 a 49 empregados; e grandes, com 50 a 500 empregados (sendo os pequenos a categoria-base).

- Região Geográfica, por meio de cinco binárias: Norte (ufn), Nordeste (ufne), Sudeste (ufse), Sul (ufs) e Centro-Oeste (ufco), sendo a região Sudeste a base;

- Binárias de efeito temporal não linear (ano).

\section{Resultados e discussão}

A Tabela 2 apresenta a evolução do número de trabalhadores formais no setor sucroenergético envolvidos na produção de cana-de-açúcar, açúcar e etanol, de modo agregado, para o Brasil e as duas principais regiões produtoras, para os anos de 2000 a 2016. Nota-se que, para o Brasil como um todo, entre 2000 e 2008, o número de empregos formais no setor registrou um aumento expressivo de 99,6\%. Em 2008, atinge-se o maior valor da série histórica avaliada, em número de pessoas ocupadas. No período subsequente, de 2008 a 2016, verifica-se queda de $38,1 \%$, com notável perda de postos de trabalho na região centro-sul (-40,3\%). Ao longo do período, a localização dos empregos seguiu predominante na região centro-sul. 
Tabela 2: Evolução do número de trabalhadores formais no Brasil e regiões de 2000 a 2016

\begin{tabular}{c|r|r|r|c}
\hline \multirow{2}{*}{ Ano } & \multicolumn{3}{|c|}{ No $^{\circ}$ trabalhadores } & $\begin{array}{c}\text { Participação relativa } \\
\text { da região Centro-Sul }\end{array}$ \\
\cline { 2 - 4 } & \multicolumn{1}{|c|}{ Brasil } & Centro-Sul & Norte-Nordeste & $61 \%$ \\
\hline 2000 & 642.848 & 392.624 & 250.224 & $69 \%$ \\
2001 & 735.890 & 433.170 & 302.720 & $62 \%$ \\
2002 & 764.593 & 475.086 & 289.507 & $61 \%$ \\
2003 & 831.062 & 504.930 & 326.132 & $62 \%$ \\
2004 & 900.768 & 557.742 & 343.026 & $63 \%$ \\
2005 & 982.604 & 618.161 & 364.443 & $67 \%$ \\
2006 & 1.113 .961 & 745.795 & 368.166 & $70 \%$ \\
2007 & 1.260 .711 & 884.270 & 376.441 & $70 \%$ \\
2008 & 1.283 .258 & 893.018 & 390.240 & $68 \%$ \\
2009 & 1.212 .271 & 823.986 & 388.285 & $67 \%$ \\
2010 & 1.181 .846 & 797.729 & 384.117 & $68 \%$ \\
2011 & 1.153 .960 & 780.107 & 373.853 & $68 \%$ \\
2012 & 1.091 .575 & 741.416 & 350.159 & $68 \%$ \\
2013 & 1.022 .320 & 699.283 & 323.037 & $68 \%$ \\
2014 & 935.009 & 632.479 & 302.530 & $67 \%$ \\
2015 & 840.281 & 561.184 & 279.097 & $67 \%$ \\
2016 & 794.911 & 532.905 & 262.006 & \\
\hline
\end{tabular}

Fonte: Elaboração própria com base em dados da RAIS.

A Tabela 3 traz o número de empregados formais por atividade, conforme a subdivisão agrícola, indústria e administrativo/outros. Percebe-se que o crescimento do número de empregados formais na indústria e nas atividades administrativas foi, em termos relativos, maior do que o de trabalhadores rurais, elevando a participação desses segmentos dentro do setor.

Esta nova configuração desenhada ao longo dos anos, que se verifica na Tabela 3, se deve, em grande medida, ao efeito de mudanças institucionais no setor, com a necessidade de ampliação da mecanização.

Destaca-se o decreto Federal no 2.661, de 8/7/98, que estabelece a eliminação gradual da queima da cana-de-açúcar no Brasil e, no âmbito dos estados, a lei estadual de São Paulo ${ }^{\circ}$ 11.241, que estipulou um cronograma gradativo de extinção da queima da cana-de-açúcar, iniciado na safra 2002, a ser totalmente banida até o ano de 2021 em áreas mecanizáveis, e até 2031 em áreas não mecanizáveis.

Conforme destacado em Moraes (2007), em 2007 foi assinado o protocolo agroambiental, entre a União da Indústria de Cana-de-Açúcar (UNICA) e o governo do Estado de São Paulo, o que antecipou eliminação da queima no Estado de São Paulo (principal região produtora no Brasil). Apesar de o protocolo não ter força de lei, ou seja, não substitui a Lei Estadual $n^{\circ} 11.241$, e não ter tido adesão obrigatória, houve grande aceitação dos produtores. Com isso, incentivou-se o processo de mecanização, devido à inviabilização da colheita manual com o fim da queima, tornando a atividade agrícola naturalmente menos trabalho intensiva. Segundo informações da CONAB (2018), na safra 2016/17, a colheita mecanizada no Brasil chegou a $89,8 \%$ da produção.

Apesar das vantagens claras associadas às melhorias das condições de trabalho com redução do corte manual, o uso de uma máquina na colheita substitui, em média, o posto de trabalho de 80 cortadores (Smeets et al. 2008). Quando comparamos o número de empregos na atividade agrícola com a pro- 
Tabela 3: Evolução do número de trabalhadores formais no Brasil nas diferentes áreas do setor sucroenergético (quantidade e percentual de representatividade dentro da atividade)

\begin{tabular}{c|r|r|r|r|r|r}
\hline \multirow{2}{*}{} & \multicolumn{2}{|c|}{ Indústria } & \multicolumn{2}{c|}{ Agrícola } & \multicolumn{2}{c}{ Administrativo/outros } \\
\cline { 2 - 7 } Quantidade & \multicolumn{1}{|c}{$(\%)$} & \multicolumn{2}{c}{ Quantidade } & $(\%)$ & Quantidade & \multicolumn{1}{c}{$(\%)$} \\
\hline 2000 & 64.454 & $10,0 \%$ & 513.416 & $79,9 \%$ & 64.978 & $10,1 \%$ \\
2001 & 67.341 & $9,2 \%$ & 593.876 & $80,7 \%$ & 74.673 & $10,1 \%$ \\
2002 & 66.162 & $8,7 \%$ & 625.676 & $81,8 \%$ & 72.755 & $9,5 \%$ \\
2003 & 78.772 & $9,5 \%$ & 671.496 & $80,8 \%$ & 80.794 & $9,7 \%$ \\
2004 & 88.807 & $9,9 \%$ & 726.005 & $80,6 \%$ & 85.956 & $9,5 \%$ \\
2005 & 95.692 & $9,7 \%$ & 795.410 & $80,9 \%$ & 91.502 & $9,3 \%$ \\
2006 & 107.694 & $9,7 \%$ & 898.697 & $80,7 \%$ & 107.570 & $9,7 \%$ \\
2007 & 118.940 & $9,4 \%$ & 1.019 .269 & $80,8 \%$ & 122.502 & $9,7 \%$ \\
2008 & 132.923 & $10,4 \%$ & 1.023 .814 & $79,8 \%$ & 126.521 & $9,9 \%$ \\
2009 & 139.010 & $11,5 \%$ & 948.565 & $78,2 \%$ & 124.696 & $10,3 \%$ \\
2010 & 144.121 & $12,2 \%$ & 908.010 & $76,8 \%$ & 129.715 & $11,0 \%$ \\
2011 & 150.632 & $13,1 \%$ & 861.093 & $74,6 \%$ & 142.235 & $12,3 \%$ \\
2012 & 146.125 & $13,4 \%$ & 804.279 & $73,7 \%$ & 141.171 & $12,9 \%$ \\
2013 & 143.460 & $14,0 \%$ & 740.275 & $72,4 \%$ & 138.585 & $13,6 \%$ \\
2014 & 135.577 & $14,5 \%$ & 665.230 & $71,1 \%$ & 134.202 & $14,4 \%$ \\
2015 & 127.358 & $15,2 \%$ & 591.533 & $70,4 \%$ & 121.390 & $14,4 \%$ \\
2016 & 126.172 & $15,9 \%$ & 555.929 & $69,9 \%$ & 112.810 & $14,2 \%$ \\
\hline
\end{tabular}

Fonte: Elaboração própria com base em dados da RAIS.

dução de cana de açúcar, percebe-se que há evidência de efeitos significativos provenientes deste processo de mecanização: entre 2008 e 2016, houve redução de $45,7 \%$ nos empregos, enquanto a produção em toneladas de cana-deaçúcar cresceu 14,5\%, acompanhando o aumento observado no Centro-Sul, entre as safras 2008/09 e 2016/17, conforme apresentado na Figura 2.

Os dados apresentados na Tabela 3 também evidenciam que a redução no número de empregos formais a partir de 2007 ocorreu inicialmente com mais intensidade entre os funcionários da área agrícola das empresas, tendo em vista o avanço rápido da mecanização. Nos últimos anos da série, entretanto, se observa redução relativa importante também na área industrial. Esse último movimento está associado ao fechamento de inúmeras usinas e ao processo de otimização e automação nas empresas.

A partir dos resultados divididos por atividade apresentados na Tabela 4, também é possível verificar que, em comparação com Moraes (2007), este estudo apresenta os mesmos dados totais para o setor agregado, porém, a divisão entre as atividades traz dados bastante distintos. Tal fato se deve à diferença na classificação dos trabalhadores entre os subsetores da indústria sucroenergética.

Conforme mencionado na seção metodológica, este presente estudo classifica os funcionários formais do setor sucroenergético de acordo com a função exercida pelos mesmos e não pela classificação da atividade da empresa em que eles estavam vinculados. Ao utilizar o CNAE da empresa empregadora, um tratorista trabalhando em uma usina cuja atividade principal registrada é a produção de açúcar, por exemplo, seria classificado na atividade "fabricação de açúcar". No presente estudo, esse mesmo funcionário foi classificado no subsetor "agrícola", pois, a despeito da atividade principal da empregadora, o mesmo exerce atividade vinculada à área rural, conforme registro advindo do 
Figura 2: Produção de cana-de-açúcar, em mil toneladas, por safra.

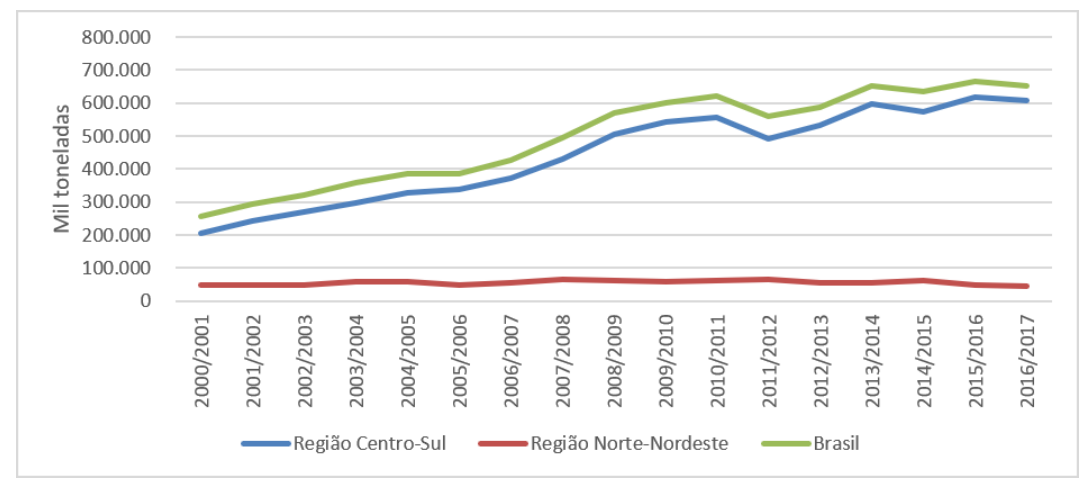

Fonte: UNICADATA (2018)

CBO. A Tabela 4 apresenta uma síntese desta diferença, para anos selecionados.

Tabela 4: Comparação entre a divisão intrassetorial de atividades do setor sucroenergético, com base em Moraes (2007) e a nova classificação proposta, para os anos de 2000 e 2005

\begin{tabular}{l|c|c|c|c|c}
\hline & & \multicolumn{3}{|c|}{ Área de Ocupação } & \\
\cline { 2 - 6 } & Ano & Agrícola & Indústria & $\begin{array}{c}\text { Administrativo/ } \\
\text { outros }\end{array}$ & Total \\
\hline Moraes (2007) & 2000 & 356.986 & 285.862 & - & 642.848 \\
& 2005 & 414.668 & 567.936 & - & 982.604 \\
\hline Classificação deste estudo & 2000 & 513.416 & 64.454 & 64.978 & 642.848 \\
& 2005 & 795.410 & 95.692 & 91.502 & 982.604 \\
\hline
\end{tabular}

Fonte: Elaboração própria com base em dados da RAIS e Moraes (2007).

A análise da Tabela 4 explicita a relevância do procedimento metodológico adotado, tendo em vista seu impacto sobre os números desagregados do setor. Ainda que com totais coincidentes, houve importante aprimoramento no que tange à distribuição desses trabalhadores entre as atividades agrícolas, industrial e administrativo/outros. Essa nova classificação também impacta possíveis análises subsequentes sobre o mercado de trabalho do setor, como os salários médios calculados para os diferentes elos desta cadeia - apesar de este dado não ser explorado em Moraes (2007). A Tabela 5 apresenta a evolução do salário médio das três atividades do setor, por região, conforme a classificação do presente estudo.

A evolução dos salários médios para três períodos distintos (2000, 2008 e 2016), separados por região produtora e escolaridade média, encontra-se nas Tabelas 6 (Brasil), 7 (Centro-Sul) e 8 (Nordeste). Observa-se uma clara evolução da escolaridade média dos trabalhadores do setor para o Brasil e para ambas as regiões analisadas, com maior destaque para a Centro-Sul. Nota-se também que os salários são positivamente correlacionados com a escolaridade média e que a média salarial (real, a preços de outubro de 2017, atualizados pelo IPCA) apresentou grande evolução no período.

Silva et al. (2019) destaca que o processo de mecanização abriu novas possibilidades de assimilação de mão de obra mais qualificada e técnica no setor, 
Tabela 5: Evolução do salário médio real, por área e região brasileira*

\begin{tabular}{|c|c|c|c|c|c|c|c|c|c|}
\hline \multirow[b]{2}{*}{ Ano } & \multicolumn{3}{|c|}{ Brasil } & \multicolumn{3}{|c|}{ Centro-Sul } & \multicolumn{3}{|c|}{ Nordeste } \\
\hline & Indústria & Outros & Agrícola & Indústria & Outros & Agrícola & Indústria & Outros & Agrícola \\
\hline 2000 & 1.932 & 2.341 & 1.049 & 2.020 & 2.595 & 1.255 & 1.663 & 1.848 & 757 \\
\hline 2001 & 2.002 & 2.368 & 1.046 & 2.097 & 2.586 & 1.269 & 1.735 & 1.942 & 759 \\
\hline 2002 & 2.066 & 2.433 & 1.082 & 2.159 & 2.657 & 1.266 & 1.781 & 1.963 & 805 \\
\hline 2003 & 2.171 & 2.296 & 1.129 & 2.286 & 2.532 & 1.336 & 1.825 & 1.825 & 840 \\
\hline 2004 & 2.078 & 2.337 & 1.120 & 2.204 & 2.589 & 1.304 & 1.711 & 1.832 & 847 \\
\hline 2005 & 2.080 & 2.333 & 1.170 & 2.223 & 2.621 & 1.365 & 1.655 & 1.775 & 862 \\
\hline 2006 & 2.145 & 2.414 & 1.262 & 2.273 & 2.668 & 1.425 & 1.721 & 1.867 & 952 \\
\hline 2007 & 2.264 & 2.569 & 1.345 & 2.395 & 2.784 & 1.495 & 1.789 & 1.986 & 1.014 \\
\hline 2008 & 2.419 & 2.798 & 1.441 & 2.574 & 3.094 & 1.629 & 1.841 & 2.012 & 1.042 \\
\hline 2009 & 2.435 & 2.980 & 1.471 & 2.593 & 3.315 & 1.675 & 1.843 & 2.072 & 1.081 \\
\hline 2010 & 2.534 & 3.009 & 1.609 & 2.684 & 3.336 & 1.847 & 1.950 & 2.115 & 1.172 \\
\hline 2011 & 2.596 & 3.091 & 1.708 & 2.732 & 3.429 & 1.962 & 2.060 & 2.139 & 1.248 \\
\hline 2012 & 2.662 & 3.135 & 1.812 & 2.802 & 3.435 & 2.093 & 2.108 & 2.250 & 1.301 \\
\hline 2013 & 2.805 & 3.233 & 1.935 & 2.982 & 3.544 & 2.252 & 2.093 & 2.295 & 1.348 \\
\hline 2014 & 2.859 & 3.268 & 1.993 & 3.063 & 3.600 & 2.361 & 2.063 & 2.275 & 1.346 \\
\hline 2015 & 2.863 & 3.297 & 2.015 & 3.080 & 3.646 & 2.391 & 2.094 & 2.271 & 1.382 \\
\hline 2016 & 2.839 & 3.286 & 2.013 & 3.062 & 3.651 & 2.386 & 2.024 & 2.216 & 1.380 \\
\hline
\end{tabular}

Fonte: Elaboração própria com base em dados da RAIS .*a preços de outubro de 2017, deflacionados pelo IPCA.

embora em uma proporção muito menor e com distintos requisitos de qualificação, criando oportunidades para tratoristas, motoristas, mecânicos e pilotos de colhedoras. Baccarin et al. (2011), que analisam apenas o período de 2007 a 2009, apontaram para uma tendência de redução na sazonalidade de emprego nas lavouras, mesmo para os trabalhadores não qualificados. Por outro lado, fatalmente houve a diminuição de postos de trabalho para um grande número de cortadores de cana desprovidos de escolaridade e experiência profissional em outras áreas (Moraes 2007, Ribeiro \& Ficarelli 2010, Ferreira Filho 2013). Os resultados das Tabelas 6, 7 e 8 ilustram evidências de tal efeito. De acordo com Abreu et al. (2009), esse fato indica a necessidade de alfabetização, qualificação e treinamento dessa mão de obra, para que ela esteja apta a realizar atividades que exijam maior escolaridade e tenham melhores possibilidades de realocação.

Tabela 6: Evolução do número de empregados e do salário médio real no Brasil por faixa de anos de estudo para 2000, 2008 e $2016^{*}$

\begin{tabular}{l|r|r|r|r|r|r}
\hline \multirow{2}{*}{ Anos de estudo } & \multicolumn{3}{|c|}{ No $^{\text {Trabalhadores }}$} & \multicolumn{3}{|c}{ Salário Real } \\
\cline { 2 - 7 } & \multicolumn{1}{|c|}{$\mathbf{2 0 0 0}$} & \multicolumn{1}{|c|}{$\mathbf{2 0 0 8}$} & $\mathbf{2 0 1 6}$ & $\mathbf{2 0 0 0}$ & $\mathbf{2 0 0 8}$ & $\mathbf{2 0 1 6}$ \\
\hline Analfabeto & 120.910 & 99.925 & 38.876 & 728 & 1.048 & 1.276 \\
$1-5$ & 359.998 & 610.853 & 248.294 & 1.170 & 1.412 & 1.712 \\
$6-9$ & 105.660 & 329.496 & 211.846 & 1.507 & 1.652 & 2.161 \\
$10-12$ & 44.179 & 211.693 & 252.306 & 1.964 & 2.043 & 2.538 \\
13 ou mais & 12.101 & 31.291 & 43.589 & 4.967 & 6.614 & 6.309 \\
\hline
\end{tabular}

Fonte: Elaboração própria com base em dados da RAIS .*a preços de outubro de 2017, deflacionados pelo IPCA.

O crescimento dos salários médios seria um efeito esperado, principalmente diante do período expansão do setor até 2008 e subsequente rápida transformação tecnológica vivenciada. No entanto, o aumento do salário médio no setor agregado pode resultar de diferentes processos intrassetoriais, com dinâmicas distintas do ponto de vista do trabalhador. Após esta análise 
Tabela 7: Evolução do número de empregados e do salário médio real na região Centro-Sul por faixa de anos de estudo para 2000, 2008 e $2016^{*}$

\begin{tabular}{l|r|r|r|r|r|r}
\hline \multirow{2}{*}{ Anos de estudo } & \multicolumn{3}{|c|}{ No $^{\mathbf{2}}$ Trabalhadores } & \multicolumn{3}{|c}{ Salário Real } \\
\cline { 2 - 7 } & \multicolumn{1}{|c|}{$\mathbf{2 0 0 0}$} & \multicolumn{1}{|c|}{$\mathbf{2 0 0 8}$} & $\mathbf{2 0 1 6}$ & $\mathbf{2 0 0 0}$ & $\mathbf{2 0 0 8}$ & $\mathbf{2 0 1 6}$ \\
\hline Analfabeto & 18.989 & 25.056 & 6.315 & 1.069 & 1.372 & 1.545 \\
$1-5$ & 241.815 & 390.281 & 119.938 & 1.304 & 1.203 & 2.064 \\
$6-9$ & 87.060 & 271.554 & 156.499 & 1.544 & 1.400 & 2.392 \\
$10-12$ & 34.957 & 178.925 & 211.448 & 1.976 & 2.125 & 2.681 \\
13 ou mais & 9.803 & 27.202 & 38.705 & 4.928 & 6.599 & 6.363 \\
\hline
\end{tabular}

Fonte: Elaboração própria com base em dados da RAIS .*a preços de outubro de 2017, deflacionados pelo IPCA.

Tabela 8: Evolução do número de empregados e do salário médio real na região Nordeste por faixa de anos de estudo para 2000, 2008 e $2016^{*}$

\begin{tabular}{l|r|r|r|r|r|r}
\hline \multirow{2}{*}{ Anos de estudo } & \multicolumn{3}{|c|}{$N^{\mathbf{0}}$ Trabalhadores } & \multicolumn{3}{|c}{ Salário Real } \\
\cline { 2 - 7 } & \multicolumn{1}{|c|}{$\mathbf{2 0 0 0}$} & \multicolumn{1}{|c|}{$\mathbf{2 0 0 8}$} & \multicolumn{1}{c|}{$\mathbf{2 0 1 6}$} & $\mathbf{2 0 0 0}$ & $\mathbf{2 0 0 8}$ & $\mathbf{2 0 1 6}$ \\
\hline Analfabeto & 101.921 & 74.869 & 32.561 & 1.069 & 1.372 & 1.545 \\
$1-5$ & 118.183 & 220.572 & 128.356 & 1.304 & 1.203 & 2.064 \\
$6-9$ & 18.600 & 57.942 & 55.347 & 1.544 & 1.400 & 2.392 \\
$10-12$ & 9.222 & 32.768 & 20.546 & 1.976 & 2.125 & 2.681 \\
13 ou mais & 2.298 & 4.089 & 4.884 & 4.928 & 6.599 & 6.363 \\
\hline
\end{tabular}

Fonte: Elaboração própria com base em dados da RAIS .*a preços de outubro de 2017, deflacionados pelo IPCA.

exploratória inicial, discute-se a segunda etapa do estudo, que lança foco nos trabalhadores individuais do setor. Com essa avaliação, explora-se como evoluíram os diferenciais salarias dentro do setor, tanto no período de expansão, quanto no período de declínio, marcado pela imposição da mecanização.

A Figura 3 mostra a distribuição dos salários reais recebidos por hora pelos empregados no setor sucroenergético. Nota-se, primeiramente, o deslocamento à direita da distribuição dos rendimentos entre os biênios 2003/04 e 2007/08, e entre 2007/08 e 2015/16. Ademais, nota-se, no último biênio, uma maior concentração de indivíduos recebendo maiores salários, com certa assimetria positiva dessa distribuição.

De forma complementar, a Figura 4 mostra a distribuição dos salários reais recebidos por hora, mas de forma desagregada, para os empregados dos elos agrícola e industrial do setor. Tanto na produção da cana quanto no elo agroindustrial verificam-se deslocamentos anuais à direita da distribuição. Todavia, há indícios de que os ganhos salariais foram maiores na agricultura. Enquanto no biênio 2003/04 havia um distanciamento relevante entre as distribuições salarias da agricultura e da indústria, em 2015/16 essas distribuições se aproximaram - ainda que com a indústria mantendo uma maior concentração de indivíduos auferindo maiores salários frente aos trabalhadores do campo.

Para aprofundar a análise acerca dos diferencias de rendimentos intrassetoriais principalmente diante de diferentes características socioeconômicas, do trabalho e locacionais dos indivíduos, a Tabela 9 apresenta as estimativas das equações de rendimentos para os 3 biênios analisados, assim como as diferenças percentuais de cada grupo frente às respectivas categorias-base para 
Figura 3: Distribuição do logaritmo neperiano do salário-hora real dos trabalhadores do setor sucroenergético ${ }^{a}$

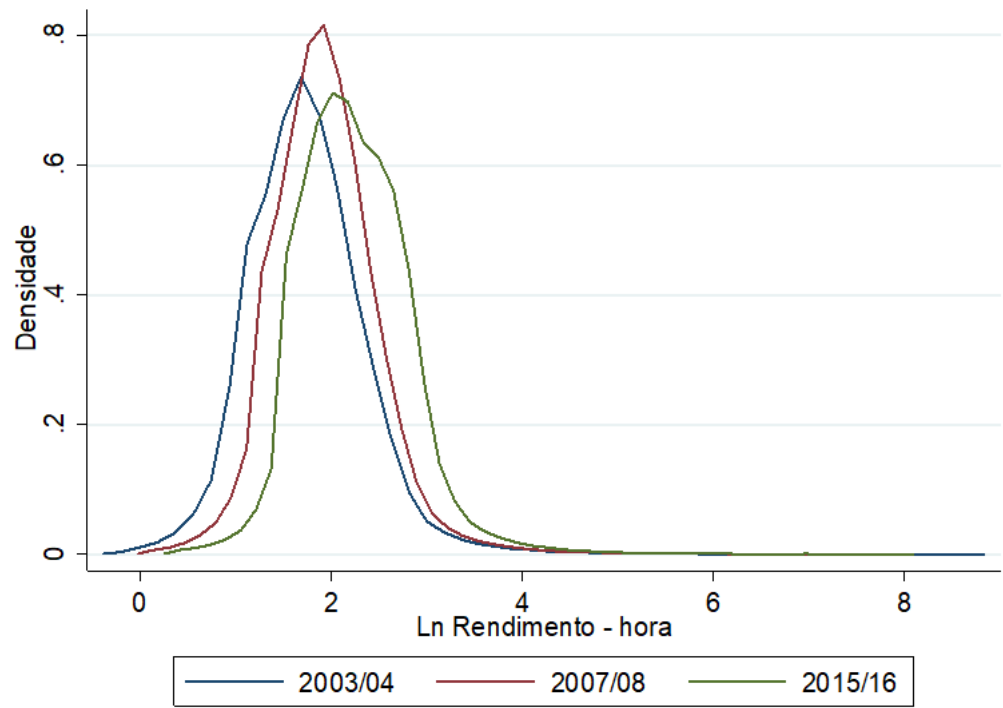

${ }^{a}$ Estimação da função de densidade Kernel com a "regra de bolso de Silverman" para a escolha a largura da janela.

Figura 4: Distribuição do logaritmo neperiano do salário-hora real dos trabalhadores do setor sucroenergético, no setor agrícola (cana) e industrial (ind)

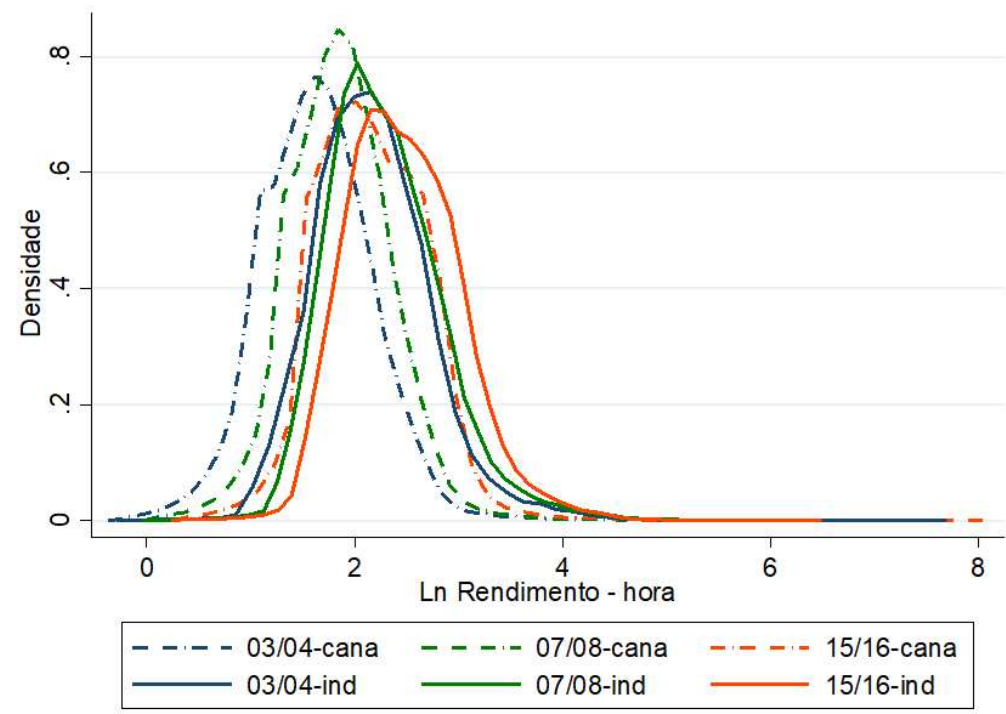


as variáveis categóricas.

Estima-se que, no setor, homens auferem salários cerca de $40 \%$ maiores frente às mulheres para cada hora trabalhada, percentual que demonstrou relativa estabilidade no período. Ainda, conforme o esperado diante da literatura teórica e empírica, verificaram-se ganhos salariais com a idade (proxy para experiência),mas a taxas decrescentes e sem variações relevantes entre os anos.

Tabela 9: Estimativas das equações de rendimentos para os anos analisados

\begin{tabular}{|c|c|c|c|c|c|c|}
\hline & $2003 / 04$ & $\left|\begin{array}{c}\text { Diferença } \\
\text { Percentual }^{\mathrm{a}}\end{array}\right|$ & $2007 / 08$ & $\left|\begin{array}{c}\text { Diferença } \\
\text { Percentual }^{\mathrm{a}}\end{array}\right|$ & $2015 / 16$ & $\mid \begin{array}{c}\text { Diferença } \\
\text { Percentual }^{\mathrm{a}}\end{array}$ \\
\hline ano & $\begin{array}{r}0,0001 \\
(0,0005) \\
\end{array}$ & 0,01 & $\begin{array}{l}0,0734^{* * *} \\
(0,0012)\end{array}$ & 7,62 & $\begin{array}{l}0,0123^{* * *} \\
(0,0006)\end{array}$ & 1,24 \\
\hline agr & $\begin{array}{l}-0,3175^{* * *} \\
(0,0017)\end{array}$ & $-27,20$ & $\begin{array}{l}-0,2620^{* * *} \\
(0,0015)\end{array}$ & $-23,05$ & $\begin{array}{l}-0,1150^{* * *} \\
(0,0015)\end{array}$ & $-10,86$ \\
\hline $\mathrm{adm}$ & $\begin{array}{l}-0,0505^{* * *} \\
(0,0021)\end{array}$ & $-4,92$ & $\begin{array}{l}-0,0692^{* * *} \\
(0,0018)\end{array}$ & $-6,69$ & $\begin{array}{l}-0,0423^{* * *} \\
(0,0018)\end{array}$ & $-4,14$ \\
\hline descol2 & $\begin{array}{l}0,1276^{* * *} \\
(0,0016)\end{array}$ & 13,61 & $\begin{array}{l}0,2152^{* * *} \\
(0,0015)\end{array}$ & 24,01 & $\begin{array}{l}0,1475^{* * *} \\
(0,0023)\end{array}$ & 15,89 \\
\hline descol3 & $\begin{array}{l}0,2139^{* * *} \\
(0,0018)\end{array}$ & 23,85 & $\begin{array}{l}0,3200^{* * *} \\
(0,0016)\end{array}$ & 37,71 & $\begin{array}{l}0,2415^{* * *} \\
(0,0024)\end{array}$ & 27,32 \\
\hline $\operatorname{descol} 4$ & $\begin{array}{l}0,3424^{* * *} \\
(0,0022)\end{array}$ & 40,83 & $\begin{array}{l}0,4314^{* * *} \\
(0,0019)\end{array}$ & 53,94 & $\begin{array}{l}0,3639^{* * *} \\
(0,0025)\end{array}$ & 43,89 \\
\hline descol5 & $\begin{array}{l}1,0061^{* * *} \\
(0,0040)\end{array}$ & 173,49 & $\begin{array}{l}1,1666^{* * *} \\
(0,0033)\end{array}$ & 221,11 & $\begin{array}{l}0,9527^{* * *} \\
(0,0033)\end{array}$ & 159,27 \\
\hline idade & $\begin{array}{l}0,0441^{* * *} \\
(0,0003) \\
\end{array}$ & & $\begin{array}{l}0,0422^{* * *} \\
(0,0002)\end{array}$ & & $\begin{array}{l}0,0532^{* * *} \\
(0,0003)\end{array}$ & \\
\hline idade 2 & $\begin{array}{l}-0,0005^{* * *} \\
(0,0000)\end{array}$ & & $\begin{array}{l}-0,0005^{* * *} \\
(0,0000)\end{array}$ & & $\begin{array}{l}-0,0006^{* * *} \\
(0,0000)\end{array}$ & \\
\hline $\operatorname{sex}$ & $\begin{array}{l}0,3408^{* * *} \\
(0,0019)\end{array}$ & 40,61 & $\begin{array}{l}0,3178^{* * *} \\
(0,0015)\end{array}$ & 37,41 & $\begin{array}{l}0,3560^{* * *} \\
(0,0019)\end{array}$ & 42,76 \\
\hline medio & $\begin{array}{l}0,0449^{* * *} \\
(0,0019)\end{array}$ & 4,59 & $\begin{array}{l}0,0372^{\text {****}} \\
(0,0018)\end{array}$ & 3,79 & $\begin{array}{l}0,1150^{* * *} \\
(0,0027)\end{array}$ & 12,19 \\
\hline gde & $\begin{array}{l}0,0967^{* * *} \\
(0,0014)\end{array}$ & 10,15 & $\begin{array}{l}0,0595^{\text {***}} \\
(0,0013)\end{array}$ & 6,13 & $\begin{array}{l}0,2629^{* * *} \\
(0,0020)\end{array}$ & 30,07 \\
\hline ufn & $\begin{array}{l}-0,2220^{* * *} \\
(0,0073)\end{array}$ & $-19,91$ & $\begin{array}{l}-0,1240^{* * *} \\
(0,0058)\end{array}$ & $-11,66$ & $\begin{array}{c}-0,2966^{\text {*** }} \\
(0,0062)\end{array}$ & $-25,62$ \\
\hline ufne & $\begin{array}{l}-0,4299^{* * *} \\
(0,0012)\end{array}$ & $-34,88$ & $\begin{array}{l}-0,1543^{\text {**\% }} \\
(0,0014)\end{array}$ & $-14,27$ & $\begin{array}{l}-0,4801^{* * \pi x} \\
(0,0013)\end{array}$ & $-38,12$ \\
\hline ufs & $\begin{array}{l}-0,3710^{* * *} \\
(0,0020)\end{array}$ & $-31,00$ & $\begin{array}{l}-0,1077^{* * *} \\
(0,0017)\end{array}$ & $-10,15$ & $\begin{array}{l}-0,3122^{* * *} \\
(0,0025)\end{array}$ & $-26,80$ \\
\hline ufco & $\begin{array}{l}-0,0777^{* * *} \\
(0,0018)\end{array}$ & $-7,41$ & $\begin{array}{l}0,0054^{* * *} \\
(0,0016)\end{array}$ & 0,54 & \begin{tabular}{|c|}
$-0,0435^{\text {***}}$ \\
$(0,0019)$
\end{tabular} & $-4,21$ \\
\hline constante & $\begin{array}{c}0,5680 \\
(0,9747)\end{array}$ & & $\begin{array}{l}-146,6644^{* * \times *} \\
-24.883\end{array}$ & & $\begin{array}{l}-24,1370^{* * *} \\
-12.021\end{array}$ & \\
\hline $\begin{array}{l}\text { N } \\
\text { sigma_u } \\
\text { sigma_e } \\
\text { rho } \\
\text { Prob > chi2 }\end{array}$ & $\begin{array}{c}1.296 .243 \\
0,421 \\
0,243 \\
0,749 \\
0,0000\end{array}$ & & $\begin{array}{c}1.589 .630 \\
0,396 \\
0,244 \\
0,725 \\
0,0000\end{array}$ & & $\begin{array}{c}849.576 \\
0,375 \\
0,188 \\
0,799 \\
0,0000\end{array}$ & \\
\hline
\end{tabular}

Fonte: Resultados originais da pesquisa. Notas: ${ }^{a}$ Diferença percentual frente aos salários da categoria base. Sendo b o coeficiente, a diferença é calculada como 100[exp(b)-1]\% (Hoffmann \& Ney 2004).

Quanto às regiões geográficas, para todos os anos, foram estimados diferenciais salariais negativos frente ao Sudeste (categoria-base). Mas, comparandose os dois primeiros biênios analisados (2003/04 com 2007/08), que caracterizam o período de forte expansão do setor, verificou-se uma aproximação das médias salariais entre as regiões. Já no período subsequente, caracterizado pela expansão da mecanização, os diferenciais de salários entre as regiões se aprofundaram novamente diante da forma geograficamente desigual que marcou esse processo.

Também conforme esperado, para os três biênios analisados verificam-se ganhos salariais positivamente relacionados com tamanho dos estabelecimen- 
tos. Esse diferencial aumentou entre 2007/08 e 2015/16. O período entre os biênios destacados corresponde a um período de crise no setor, com o fechamento de várias unidades industriais. Com isso, tal resultado de aprofundamento da vantagem salarial dos estabelecimentos de maior porte no período também pode indicar um melhor desempenho destas empresas no enfrentamento do período de retração (empresas mais eficientes devem ter apresentado maior taxa de crescimento nesse período).

Voltando-se às principais variáveis de interesse do estudo, verifica-se uma aproximação entre os salários-hora médios pagos na atividade agrícola e aqueles pagos para os trabalhadores industriais e administrativos, controladas as demais características. Enquanto os salários administrativos se mantiveram praticamente estáveis frente aos industriais, o diferencial entre os salários administrativos e os agrícolas recuou de $27,2 \%$ em 2003/04 para 23,05\% em 2007/08 e então para apenas 10,86\% em 2015/16 (Tabela 9).

Seja no primeiro período analisado, marcado pelo crescimento e maior demanda por investimentos no setor, ou no segundo, marcado pela importante transformação tecnológica e pela substituição do trabalho pouco qualificado, envolvido no corte manual, por empregos de qualificação - apesar do menor número absoluto de empregos -, evidencia-se que o dinamismo do setor se refletiu em ganhos salariais.

Entre 2003/04 e 2007/08, de modo geral, aumentaram os diferenciais salariais relacionados ao grau de instrução no setor, sobretudo para os trabalhadores com mais de 13 anos de estudo, que, no primeiro biênio, auferiam salários $173,49 \%$ maiores que os recebidos por pessoas sem instrução, percentual que aumentou para $221,11 \%$ no biênio $2007 / 08$. Por outro lado, comparando-se 2007/08 e 2015/16, marcou o setor a diminuição dos diferenciais salariais por níveis de instrução.

Conforme destacado em Pianta et al. (2009), o avanço tecnológico pode, por um lado, causar a ampliação das diferenças salariais dentro de uma indústria quando partes dos melhores retornos obtidos são apropriadas por gestores e trabalhadores mais qualificados. Por outro lado, se o avanço tecnológico proporciona a difusão do conhecimento de modo que novos processos e bens de capital distribuem competências e aumentam a produtividade dos trabalhadores menos qualificados, esse pode levar à redução de diferenciais salariais. No caso do setor sucroenergético entre 2007 e 2016, evidências apontam para uma maior força do processo em que mesmo os trabalhadores menos qualificados auferem ganhos com o avanço tecnológico.

Aprofundando-se na questão regional, a Tabela 10 apresenta as estimativas das equações de rendimentos para os biênios inicial e final, desagregando os trabalhadores das regiões Centro-Sul e Nordeste. Em ambas as regiões, verificam-se tendências similares àquelas observadas em âmbito nacional e descritas anteriormente. Porém, comparando-se a região Nordeste com o Centro-Sul, verifica-se que a região Nordeste ainda concentra maiores desigualdades entre os salários-hora médios pagos na atividade agrícola e aqueles pagos para os trabalhadores industriais e administrativos, controladas as demais características.

Apesar dessa característica, é importante mencionar que a diferença entre o salários dos trabalhadores das áreas administrativas e agrícola tem apresentado recuo não desprezível, passando de $42,68 \%$ em 2003/04 para 21,95\% em 2015/16. O diferencial de salário administrativos, por sua vez, se manteve 
praticamente estável no Nordeste frente aos industriais no período em análise.

Em relação à escolaridade, o Nordeste também apresentou diferencial mais elevado para os trabalhadores com maior anos de estudo, visto que o rendimento aumenta de maneira mais significativa entre as diferentes faixas de escolaridade.

Tabela 10: Estimativas das equações de rendimentos por região (Nordeste e Centro-Sul)

\begin{tabular}{l|c|c|c|c}
\hline \multirow{2}{*}{ agr } & \multicolumn{2}{|c|}{$2003 / 2004$} & \multicolumn{2}{c}{$2015 / 2016$} \\
\cline { 2 - 5 } & Nordeste & Centro-Sul & Nordeste & Centro-Sul \\
\hline adm & $\begin{array}{c}-0,4268^{* * *} \\
(0,0040)\end{array}$ & $\begin{array}{c}-0,2902^{* * *} \\
(0,0020)\end{array}$ & $\begin{array}{c}-0,2195^{* * *} \\
(0,0031)\end{array}$ & $\begin{array}{c}-0,0817^{* * *} \\
(0,0017)\end{array}$ \\
\hline descol2 & $\begin{array}{c}-0,0763^{* * *} \\
(0,0050)\end{array}$ & $\begin{array}{c}-0,0593^{* * *} \\
(0,0027)\end{array}$ & $\begin{array}{c}-0,0781^{* * *} \\
(0,0039)\end{array}$ & $\begin{array}{c}-0,0342^{* * *} \\
(0,0024)\end{array}$ \\
\hline descol3 & $\begin{array}{c}0,1239^{* * *} \\
(0,0022)\end{array}$ & $\begin{array}{c}0,0619^{* * *} \\
(0,0029)\end{array}$ & $\begin{array}{c}0,1239^{* * *} \\
(0,0027)\end{array}$ & $\begin{array}{c}0,1746^{* * *} \\
(0,0056)\end{array}$ \\
\hline descol4 & $\begin{array}{c}0,2820^{* * *} \\
(0,0037)\end{array}$ & $\begin{array}{c}0,1117^{* * *} \\
(0,0031)\end{array}$ & $\begin{array}{c}0,1747^{* * *} \\
(0,0031)\end{array}$ & $\begin{array}{c}0,2823^{* * *} \\
(0,0056)\end{array}$ \\
\hline descol5 & $0,4597^{* * *}$ & $0,2270^{* * *}$ & $0,2957^{* * *}$ & $0,3988^{* * *}$ \\
$(0,0054)$ & $(0,0034)$ & $(0,0038)$ & $(0,0056)$ \\
\hline Controle idade & $\begin{array}{c}1,3454^{* * *} \\
(0,0190)\end{array}$ & $\begin{array}{c}0,8306^{* * *} \\
(0,0080)\end{array}$ & $\begin{array}{c}1,0555^{* * *} \\
(0,0137)\end{array}$ & $\begin{array}{c}0,9569^{* * *} \\
(0,0071)\end{array}$ \\
\hline Controle tam. & Sim & Sim & Sim & Sim \\
estabelecimento & Sim & Sim & Sim & Sim \\
\hline Controle anual & Sim & Sim & Sim & Sim \\
\hline Controle estados & Sim & Sim & Sim & Sim \\
\hline
\end{tabular}

Fonte: Resultados originais da pesquisa. Notas: Erro padrão nos parênteses; ${ }^{*} \mathrm{p}<$ $0,10,{ }^{* *} \mathrm{p}<0,05,{ }^{* * *} \mathrm{p}<0,01$.

\section{Conclusões}

A proposta metodológica apresentada para a divisão dos trabalhadores do setor sucroenergético entre as atividades agrícola, industrial e administrativo/outros permitiu uma melhor avaliação da estrutura de distribuição dos empregos neste mercado. Comparativamente a estudos anteriormente realizados, verifica-se uma maior proporção de empregos na área agrícola, que antes eram avaliados como empregos industriais devido à elevada integração vertical do setor.

$\mathrm{Na}$ análise do período selecionado, a agroindústria sucroenergética sofreu diversas transformações de ordem institucional e mercadológica, que geraram diferentes efeitos sobre o mercado de trabalho no setor.

Os resultados destacam a grande expansão do número de empregos e salários até 2008, com diferenciais de salários entre os trabalhadores do setor, em geral apresentando redução. Mas houve queda no número de ocupações no período posterior até 2016. Por outro lado, nesse mesmo período, avaliou-se um crescimento da qualidade das ocupações, com crescimento da proporção de trabalhadores com maior escolaridade no total de empregos e elevação dos salários reais. 
Destacou-se na configuração deste contexto o processo de mecanização da colheita, notadamente na região Centro-Sul, o que impactou na redução significativa de empregos na área agrícola. Porém, o avanço tecnológico trouxe evoluções importantes, como a possibilidade de empregos de melhor qualidade e ganhos salariais, que foram verificados inclusive entre os trabalhadores menos qualificados. Também se verificaram efeitos da crise do setor, que teve influência expressiva principalmente na queda de empregos na indústria entre 2008 e 2016.

Por fim, é preciso reconhecer que a análise conduzida aqui não tem a pretensão de esgotar o assunto. Novos trabalhos visando avaliar o impacto da mecanização sobre o fluxo migratório dos trabalhadores rurais, os ganhos de produtividade do trabalho nos diferentes subsetores da indústria sucroenergética e as novas ocupações dos antigos cortadores de cana-de-açúcar, por exemplo, serão fundamentais para ampliar o conhecimento sobre o tema e direcionar medidas de caráter público ou privado nessa área.

\section{Referências Bibliográficas}

Abreu, D., Moraes, L. A., Nascimento, E. N. \& Oliveira, R. A. (2009), 'Impacto social da mecanização da colheita de cana-de-açúcar', Revista de Medicina do Trabalho 4(6), 3-11.

Baccarin, J. G. (2015), 'Mudanças tecnológicas recentes e ocupação canavieira no centro-sul do Brasil', Revista Laborativa 4(1), 56-78.

Baccarin, J. G., Gebara, J. J. \& Borges Junior, J. C. (2011), 'Expansão canavieira e ocupação formal em empresas sucroalcooleiras do Centro-Sul do Brasil, entre 2007 e 2009', Rev. Econ. Sociol. Rural 49(2), 493-506.

Beiral, P. R. S. (2011), O mercado brasileiro de etanol: concentração e poder de mercado sob a ótica da Nova Organização Indústria Empírica. Dissertação de Mestrado, Master's thesis, Piracicaba: ESALQ-USP. (Dissertação de Mestrado).

Castro, N. R., Almeida, A. N., Barros, G. S. C. \& Morais, A. C. P. (2016), 'Diferencial de rendimentos no agronegócio: uma análise a partir dos dados da PNAD Contínua', in $54^{\circ}$ Congresso da Sociedade Brasileira de Economia, Administração e Sociologia Rural - Anais Eletrônicos Sober 2016, Maceió: SOBER.

CONAB (2017). Perfil do Setor do Açúcar e do Etanol no Brasil, v.1, Brasília: CONAB.

CONAB (2018). Acompanhamento da Safra Brasileira - Cana-de-Açucar. Terceiro Levantamento, v. 5 - Safra 2018/19, v. 5, Brasília: CONAB, p. 1-71.

Ferreira Filho, J. B. S. (2013), 'Food security, the labor market, and poverty in the brazilian bio-economy', Agricultural Economics 44, 85-93.

Gilio, L. (2015), Análise dos impactos socioeconômicos da expansão do setor sucroenergético, Master's thesis, Piracicaba: ESALQ-USP. (Dissertação de Mestrado). 
Gilio, L. \& Castro, N. R. (2016), 'Avaliação de aspectos limitantes ao crescimento do etanol e o setor sucroenergético no Brasil', Revista Eletrônica de Energia 6(1), 58-74.

Gilio, L., Moraes, M. A. F. D., Moreira, G. C. \& Guardia, A. F. T. S. (2015), 'Restrição à Propriedade e Arrendamento de Terras por Estrangeiros: Evidências sobre Efeitos nas Decisões de Investimento do Setor Sucroenergético', Economic Analysis of Law Review 6, 356-372.

Greene, W. H. (2008), Econometric Analysis, Fith edition, USA, Upper Saddle River, NJ.

Hoffmann, R. \& Ney, M. G. (2004), 'Desigualdade, escolaridade e rendimentos na agricultura, indústria e serviços, de 1992 a 2002', Economia e Sociedade 13(2), 51-79.

Hoffmann, R. \& Oliveira, F. C. R. (2008), 'Evolução da remuneração das pessoas empregadas na cana-de-açúcar e em outras lavouras, no Brasil e em São Paulo'. in $46^{\circ}$ Congresso da Sociedade Brasileira Economia, Administração e Sociologia Rural - Anais do $46^{\circ}$ Congresso da SOBER, Rio Branco: SOBER.

Kutas, G., Phillips, L. \& Sousa, E. L. (2016), 'Perspectivas do Mercado Internacional', AgroAnalysis 36(5), 43.

Moraes, M. A. F. D. (2007), 'O mercado de trabalho da agroindústria canavieira: desafios e oportunidades', Economia Aplicada 11(4), 605-619.

Moraes, M. A. F. D. \& Zilberman, D. (2014), Production of ethanol from sugarcane in Brazil, London: Springer.

URL: $h t t p: / / d x$.doi.org/10.1007/978-3-319-03140-8

Moraes, M. A. F. D., Zilberman, D. \& Rodrigues, L. (2014), The free market: The profounf changes and the new agenda, New York: Springer, cap. 14.

Moraes, M. L. \& Bacchi, M. R. P. (2014), 'Etanol, do início às atuais fases de produção', Revista de Política Agrícola 4, 5-22.

Oliveira, F. C. (2009), Ocupação, emprego e remuneração na cana-de-açúcar e em outras atividades agropecuárias no Brasil, de 1992 a 2007, Master's thesis, Piracicaba: ESALQ-USP. (Dissertação de Mestrado).

Pianta, M., Angelini, E. C. \& Farina, F. (2009), 'Innovation and wage polarisation in Europe', International Review of Applied Economics 23(3), 309-325.

Ribeiro, H. \& Ficarelli, T. R. A. (2010), 'Sugarcane Burning and Perspectives for Harvesters in Macatuba', Saúde e Sociedade 19(1), 48-63.

Rodrigues, L. \& Bacchi, M. R. P. (2016), 'Light fuel demand and public policies in Brazil, 2003-2013', Applied Economics 54, 5300-5313.

Santos, G. R., Garcia, E. A. \& Shikida, P. F. A. (2015). A Crise na Produção do Etanol e as Interfaces com as Politicas Públicas, Brasília: IPEA.

URL: Disponivel em: < http://repositorio.ipea.gov.br/handle/11058/4259>

Silva, R. P., Gilio, L. \& Castro, N. R. (2019), 'Impactos da eliminação da queimada da cana sobre o setor sucroenergético: uma análise de equilíbrio geral'. Revista Econômica do Nordeste, Nordeste 50(1), 9-21. 
Smeets, E., Junginger, M., Faaij, A., Walter, A. \& Dolzan, P. (2008), 'The sustainability of Brazilian ethanol - An assessment of the possibilities of certified production', Biomass \& Bioenergy 32(8), 781-813.

Solowiejczyk, A. \& Costa, R. P. F. (2013), 'O controle de preço da gasolina pode ser fatal', Agroanalysis 82, 21-22. (acesso em abril de 2017).

URL: Disponivel em: <http://www.agroanalysis.com.br/materia_detalhe.php ?idMateria $=1415>$

Toneto Junior, R. \& Liboni, L. B. (2008), 'Evolução recente do mercado de trabalho da cana-de-açúcar no Brasil (1995-2006)', Organizações Rurais e Agroindustriais 10(3), 455-474.

UNICADATA (2018), Histórico de produção e moagem. (acesso em abril de 2018).

URL: Disponivel em: <http://www.unicadata.com.br/historico-de-producao-emoagem.php?idMn=32EtipoHistorico $=4>$ 